\title{
Consolidação internacional da paz versus percepções locais sobre a paz: encontros e desencontros
}

\author{
International peacebuilding vs. local perceptions of peace: Encounters and \\ misencounters
}

\section{Roberta Holanda Maschietto ${ }^{1}$}

\section{RESUMO}

Este artigo discute a virada local na análise da consolidação da paz, em especial o conceito de paz híbrida, alertando para as limitações desse debate no que concerne à ótica cultural utilizada. Argumenta-se que, à medida que a discussão sobre paz híbrida está atada à da paz liberal e enfatiza dinâmicas de resistência, ela limita a própria discussão da dimensão cultural ao excluir da análise aspectos mais interpretativos sobre a paz, não necessariamente relacionados à paz liberal.

Palavras-chave: Consolidação da paz. Virada local. Paz liberal.

\begin{abstract}
This article discusses the local turn in peacebuilding and the concept of hybridity, highlighting the limitations related to cultural analysis framework utilised in this discussion. It argues that, as long as this debate is tight to the liberal peace (and the expressions of resistance to it), it limits the cultural analysis by excluding a broader discussion that includes alternative interpretations and perceptions of peace that are not necessarily related to the liberal peace.
\end{abstract}

Key-words: peacebuilding; local turn; liberal peace.

\section{INTRODUÇÃO}

Ao longo dos últimos 20 anos houve uma expansão significativa da literatura voltada para a chamada "virada local" nos estudos sobre a construção/consolidação da paz (peacebuilding). ${ }^{2}$ Em linhas gerais, em suas diferentes vertentes, essa literatura

${ }^{1}$ Pesquisadora de pós-doutorado no Centro de Estudos Sociais da Universidade de Coimbra, em Coimbra, Portugal.

${ }^{2}$ A literatura em inglês utiliza o termo peacebuilding. Em português, esse termo é traduzido ora como "construção", ora como "consolidação" da paz. Neste texto, esses dois termos serão 
advoga que os atores locais - aqueles que vivenciaram o conflito armado - adquiriram um posicionamento central na análise e na formulação e implementação de políticas voltadas para a paz (LEDERACH, 1997; RAMSBOTHAM et al., 2005; RICHMOND, 2005; ROBERTS, 2011; MAC GINTY; RICHMOND, 2013; HUGHES et al., 2015; PAFFENHOLZ, 2015). Por sua vez, as perspectivas epistemológicas subjacentes a esse debate variam significativamente. Assim, enquanto na primeira parte da década de 1990 a preocupação com o nível local concentrou-se na literatura mais voltada para a resolução e a transformação de conflitos (LEDERACH, 1997; RAMSBOTHAM; WOODHOUSE, 2005), a partir de meados dos anos 2000, surgiu uma literatura eminentemente crítica, com influências pós-marxistas, póscoloniais e pós-estruturalistas (CHANDLER, 2006; PUGH et al., 2011; MAC GINTY; RICHMOND, 2013).

Este artigo dialoga primordialmente com a literatura mais recente sobre a virada local, em especial aquela de influência pós-colonial, que incorporou o conceito de hibridismo como elemento explicativo central na análise da consolidação da paz. Em linhas gerais, o conceito de "paz híbrida" reflete o papel ativo - a "agência" - dos atores "locais" em relação às intervenções internacionais (MAC GINTY, 2010). Mais do que isso, a discussão acerca do hibridismo representa uma reação ao discurso dominante da paz liberal e sua acepção problem-solving, ao contestar a ideia de que os atores locais são meramente objetos de intervenção que aceitam e/ou se submetem às diretrizes políticas e culturais oriundas dos atores externos (fundamentalmente atores do "norte" global).

A discussão sobre a paz híbrida contribuiu em grande medida para a mudança do foco de análise no debate sobre a consolidação da paz - não mais considerando apenas a visão do interveniente (dos "doadores" e das instituições internacionais), mas também a dos atores locais (elites e não elites). Por outro lado, tal discussão ainda é fundamentalmente pautada no problemático conceito da "paz liberal", utilizado como ponto de partida do debate. 0 presente artigo visa problematizar essa característica da discussão sobre o hibridismo nos processos de consolidação da paz ao enfatizar o aspecto cultural e interpretativo que pauta as interações entre os diversos agentes envolvidos nesses processos.

utilizados como sinônimos, pois, não obstante a diferença semântica entre ambos, a discussão teórica existente remete ao conceito mais genérico de peacebuilding em inglês, o que inclui quaisquer atividades que se desenvolvem após a cessação formal do conflito armado. 
O argumento proposto é que a dimensão cultural local, ou seja, a lente pela qual os atores locais interpretam o conceito de paz (inclusive a paz promovida pelos atores internacionais), é fundamental para a compreensão acerca do alinhamento e/ou distanciamento das ações internacionais de consolidação da paz e a realidade local. Isso, por sua vez, afeta o sucesso e a sustentabilidade da paz fomentada por essas intervenções a longo prazo. No âmbito teórico-conceitual, argumenta-se que, ao mesmo tempo em que a discussão sobre paz híbrida amplia o espaço para se discutir a dimensão cultural subjacente à consolidação da paz, o fato de ela estar atada à paz liberal limita a própria discussão da dimensão cultural ao, indiretamente, excluir do centro da análise aspectos não diretamente relacionados à paz liberal. Em outras palavras, embora o arcabouço conceitual da paz híbrida ofereça espaço para se explorar a dimensão interpretativa e subjetiva da paz, na prática, a literatura tem enfatizado as dinâmicas de resistência à paz liberal, minimizando, dessa forma, as dinâmicas de alinhamento à paz liberal, bem como aquelas que não se relacionam a ela nem por alinhamento nem por oposição.

O artigo está estruturado em quatro partes, além da introdução e da conclusão. A próxima seção apresenta os pressupostos básicos daquilo que se convencionou chamar de "paz liberal" e que permeia a lógica das ações ligadas à consolidação da paz. A seção seguinte discute os principais aspectos da chamada "virada local", bem como as suas limitações analíticas, em especial no que concerne à discussão sobre cultura e o papel da subjetividade local. A terceira seção discute algumas interpretações culturais sobre o conceito de paz e sua relação (e distanciamento) com a paz liberal. A última seção apresenta alguns exemplos que realçam o contraste entre a lógica da paz liberal e a lógica que permeia as visões e expectativas de paz dos atores locais na análise do caso moçambicano. A seção baseia-se em pesquisa de campo realizada pela autora, em 2012, no norte de Moçambique e que incluiu uma série de entrevistas e grupos focais com habitantes da zona rural no distrito de Angoche, na província de Nampula. A questão que guiou a pesquisa foi: "Qual é a percepção de mudança dessas comunidades desde o fim da guerra?" (MASCHIETTO, 2015). As respostas obtidas inspiraram o tema deste artigo e originaram uma pesquisa que se encontra em andamento, focada nas interpretações sobre paz em cenários de consolidação da paz. 


\section{OS PRESSUPOSTOS DA PAZ LIBERAL}

Uma vez que a crítica apresentada no discurso da virada local é baseada na crítica à paz liberal, é importante entender o que essa última representa. A ideia de paz liberal popularizou-se no debate sobre consolidação da paz, especialmente a partir do livro seminal de Roland Paris, At War's End: Building Peace After Civil Conflict, de 2004. Nessa obra, Paris partiu do pressuposto de que o elemento central que guiava as operações de paz para a consolidação da paz nos países que saíam de guerras civis era a liberalização. Nesse sentido, a liberalização política (entendida primordialmente como a implementação formal da democracia multipartidária, a realização de eleições e a existência de espaço para a atuação da sociedade civil) e econômica (ou seja, a consolidação de uma economia de mercado, refletindo a agenda neoliberal, com ênfase na privatização e na redução do Estado) seria vista como um pilar para a promoção da estabilidade, servindo, assim, como um mecanismo de prevenção de conflito.

Em sua análise de 14 casos de construção da paz ao longo da década de 1990, Paris (2004) concluiu que as limitações ligadas a essas atividades seriam resultantes da forma como elas foram implementadas - em circunstâncias de extrema fragilidade institucional. Daí a sua proposição de que a liberalização em países recém-saídos da guerra deveria ser precedida da institucionalização, ou seja, da reconstrução das instituições basilares do Estado.

Não obstante a sua crítica ligada à forma como as ações internacionais eram realizadas, em essência, o discurso de Paris reteve a tese preexistente de que a liberalização política e econômica constituía um elemento central na consolidação da paz e que, em última instância, algum grau de engenharia social seria necessário para a construção e a consolidação da paz. Em linhas gerais, essa tese - que sustenta o discurso da paz liberal - emana de duas outras teses: de um lado, provém da teoria da paz democrática (PARIS, 2004; MAC GINTY, 2006); de outro, é pautada na ideia de que livrecomércio e integração econômica contribuem para a estabilidade em regiões propensas a conflitos por meio da promoção do crescimento econômico e, subsequentemente, da redução da pobreza e das desigualdades (WILLETT, 2011; HEATHERSHAW, 2008). Na prática, no entanto, ambas as teses são bastante problemáticas em contextos de pósguerra. 
De um lado, a teoria da paz democrática foi desenvolvida para explicar as relações entre Estados e não dentro dos Estados. De fato, no âmbito doméstico, especificamente após o fim de um conflito violento, a democratização (particularmente a realização de eleições) pode acirrar tensões que existiram até o momento da assinatura do acordo de paz. Um dos motivos para tanto é o alto grau de tensão existente entre partidos políticos que, até pouco tempo antes, eram inimigos em guerra e, portanto, ainda não superaram o alto grau de desconfiança em relação ao outro, ao mesmo tempo em que ainda não confiam no novo sistema político (MANNING, 2009). Além disso, e de forma relacionada, observa-se nesses cenários a ausência de demanda por democracia por parte das elites, uma vez que a consolidação do processo democrático exige repensar a distribuição de recursos econômicos e políticos (ZÜRCHER, 2011).

De outro lado, no que concerne à liberalização econômica, na prática não existe uma correlação clara entre liberalização comercial e crescimento econômico e menos ainda entre aquela e a redistribuição do dividendo da paz (WILLETT, 2011; DONAIS, 2012). Assim, um dos grandes desafios para países que acabaram de sair de um conflito violento é justamente a busca do equilíbrio entre o papel do Estado e o mercado (ver, por exemplo, MAC GINTY, 2006; PUGH, 2010).

De certa forma, a emergência da centralidade da construção do Estado como pilar da consolidação da paz, em especial depois do 11 de Setembro, surgiu justamente do reconhecimento de que as reformas de mercado e democráticas (eleições) por si sós não eram suficientes para evitar o ressurgimento da violência (PARIS, 2004; SABARATNAM, 2011). No entanto, é notável que, não obstante a reforma do Estado tenha ganhado primazia, a relevância da democracia e da economia de mercado continua como elemento central na agenda internacional de consolidação da paz. Aliás, a ênfase na relevância do Estado (mais especificamente de suas instituições formais) tem se mantido como elemento crucial mesmo após a inclusão da preocupação com a sociedade civil e a criação de mais espaços para participação nessa agenda (MAC GINTY, 2006; BORGES; MASCHIETTO, 2016). Mais do que isso, tem se mantido intacta a "necessidade" de intervir e exportar modelos de gestão estatal e social percebidos como "melhores", "mais desenvolvidos", mais "eficientes", mesmo que não haja evidência para confirmar que essa "exportação" seja de fato eficaz. 
Em grande medida, esse pressuposto da "necessidade de intervir" advém do paradigma da modernidade, subjacente à lógica das intervenções para promoção e consolidação da paz. Esse paradigma é baseado em valores que se desenvolveram na história do Ocidente e que privilegiam determinados princípios acima de outros, como, por exemplo, o papel das liberdades individuais em oposição a dinâmicas comunitárias. Nesse sentido, a ideia de progresso e universalidade das normas que pautam essa agenda se choca com elementos culturais que vão contra esses pressupostos (MAC GINTY, 2006; RICHMOND, 2011 e 2014). No que concerne às ações de consolidação da paz, no entanto, talvez o maior problema subjacente à modernidade resida no seu papel discursivo que legitima as intervenções internacionais, obscurecendo o potencial e a eficácia de modelos alternativos de regulação social. Conforme destaca Fetherston (2000, p. 190), “o conhecimento produzido por este discurso é racional, universal e permanente. 0 projeto final da modernidade é o conhecimento total, o poder total, o iluminismo total, o fim da história e, simultaneamente, o fim da diferença”, ou seja, parte-se do pressuposto de que existe um único modelo ideal e que, num mundo onde esse modelo supostamente funciona em certos países (do "norte global"), nada mais natural do que "exportar" esse modelo para outras sociedades.

Não obstante esse traço universal, há que se destacar as variações e nuances ligadas à "exportação" da paz liberal ao longo do tempo e como esse próprio paradigma sofre alterações. Richmond (2006), por exemplo, identifica diferentes gradações da paz liberal, pautadas nas diversas nuances do próprio conceito de paz. Essas nuances seriam respectivamente: a paz do vencedor (que advém de uma vitória militar), a paz institucional (que enfatiza a dimensão legal do contrato social e que fundamenta a lógica da construção do Estado ou statebuilding), a paz constitucional (baseada em democracia, livre-comércio e valores cosmopolitas que primam pela liberdade dos indivíduos) e a paz civil (resultante de ação civil direta e mobilização para conquistar determinados direitos). Richmond nota que esses aspectos da paz liberal são tanto contraditórios quanto complementares. Ao mesmo tempo, cada um carrega certa bagagem intelectual normativa e empírica, o que, por sua vez, leva a perturbações dentro do próprio processo de consolidação da paz, posto que existem disputas pela prevalência de uma ou outra nuance (RICHMOND, 2006). Por sua vez, a predominância de uma ou outra nuance da paz liberal leva a diferentes tipos de gradação da paz liberal - respectivamente, a ortodoxa, a emancipatória e a conservadora. 
De forma semelhante, Heathershaw identifica três nuances do discurso da paz liberal, que se baseiam nas conotações do termo "paz" discutidas por Michael Banks em 1987. A primeira nuance remete à ideia de consolidação da paz como ligada à reforma democrática (democratic peacebuilding), a segunda ressalta o papel da sociedade civil e a terceira enfatiza a construção do Estado (statebuilding). Esses discursos sustentam diferentes metaideias. No primeiro caso, o valor central é liberdade, no segundo prevalece o papel da justiça e, no terceiro, a preocupação central é a ordem.

Seguindo a ótica de Richmond e Heathershaw, essas variações da paz liberal, muito embora apresentem contradições que se exprimem particularmente na forma como as políticas para a paz serão aplicadas, não chegam a abalar os valores mais essenciais desse paradigma, ou seja, sua tônica universalizante. Isso, por sua vez, causa distúrbios (em especial resistência) quando de sua implementação em contextos não ocidentalizados.

Dito isso, vale observar que, não obstante a crescente literatura que aceita a "paz liberal" como um paradigma existente, existem críticas relativas à validade desse conceito. Jan Selby (2013), por exemplo, questiona a sua validade desconstruindo o próprio discurso que sustenta a paz liberal. Ele argumenta que, a despeito de a literatura voltada para a crítica da paz liberal ter trazido à tona elementos extremamente importantes para a compreensão das políticas de consolidação da paz, o próprio conceito de paz liberal é minimalista e tendencioso e, em última instância, limita a análise do que ocorre nesse campo. De fato, o uso do termo exagera a dimensão "liberal" das intervenções de paz, minimizando outros fatores importantes, como geopolítica e estratégia, que também têm um papel crucial na formulação e implementação dessas práticas.

Essa crítica é extremamente válida. No entanto, vale notar que os princípios normativos da paz liberal sustentam a própria legitimidade das ações internacionais, pois se presume, no cenário global, que os princípios ligados à liberalização - especialmente à liberalização política - são eminentemente “bons". Nesse sentido, grande parte da crítica que surgiu e que culminou na chamada "virada local", analisada abaixo, reside, justamente na contestação dessa dimensão normativa, que confunde valores "ocidentais" com valores "universais". 


\section{A “VIRADA LOCAL” NA CONSOLIDAÇÃO DA PAZ: CONTRIBUIÇÕES E LIMITAÇÕES}

A chamada "virada local" nos estudos sobre a consolidação da paz surgiu justamente a partir da crítica ao universalismo embutido em sua prática. Apesar da utilização corrente no singular, é possível identificar duas "viradas locais" distintas (PAFFENHOLZ, 2015). A primeira se deu ainda na década de 1990, quando do próprio desenvolvimento da agenda da consolidação para a paz. O foco dessa "virada" residia na promoção do engajamento dos atores locais nos processos ligados à consolidação da paz (peacebuilding from below) e apresentava uma preocupação prática muito marcada, com vistas a propor métodos mais inclusivos para diálogo e resolução de conflito de forma a empoderar os atores locais e promover a reconciliação (LEDERACH, 1997; RAMSBOTHAM et al., 2005). Nesse sentido, havia uma ênfase no aspecto colaborativo entre os atores internacionais e locais de todas as esferas.

Em contrapartida, a segunda "virada local" se desenvolveu no início dos anos 2000, em resposta ao desenvolvimento das operações de paz da ONU e seus inúmeros problemas. Esse debate assumiu um contorno crítico voltado para o próprio projeto dessas operações, nomeadamente a construção dos Estados (statebuilding). Diferentemente dos anos 1990, o objetivo aqui não é a promoção da reconciliação, mas a própria problematização do paradigma que sustenta a legitimidade das operações de paz. Em especial, dada a influência pós-colonial desse debate, critica-se o viés ocidental dessas atividades, em oposição à priorização do viés local - daí a ênfase nessa literatura nas dinâmicas de resistência local (MAC GINTY, 2010; RICHMOND, 2011 e 2014; PAFFENHOLZ, 2015).

A nova "virada local" possui um apelo emancipador: ela rejeita tanto a universalidade dos valores embutidos na agenda da consolidação da paz quanto as próprias prioridades da agenda - que, por suposto, exclui dimensões que, aos olhos das populações locais, são, muitas vezes, mais importantes (como, por exemplo, bem-estar social, distribuição de renda, etc.). Nesse sentido, essa agenda também contempla a rejeição da abordagem "problem solving" e mecanicista que sustenta as ações voltadas para a paz, dando voz aos agentes marginalizados (ou subalternos) (MAC GINTY; RICHMOND, 2013; RICHMOND, 2011 e 2014).

Um dos conceitos centrais presentes no debate mais recente da virada local, e que captura essa crítica, é o de "paz híbrida". Esse termo advém do conceito anterior de 
“ordens políticas híbridas” (BOEGE et al., 2009), elaborado a fim de criticar a visão binária que sustenta o discurso sobre Estados frágeis/falidos. De acordo com Boege et al. (2009), os chamados Estados "frágeis" são, na verdade, espaços onde existe uma reivindicação competitiva pelo poder e pela lógica que rege a ordem social. Essa dinâmica envolve o choque entre formas tradicionais e informais de governança social e a forma de funcionamento do Estado formal, levando a um resultado híbrido, posto que uma lógica não consegue se sobrepor a outra. No caso da paz híbrida, esta se constitui a partir da tensão que existe entre as práticas e as instituições "exportadas" (e que refletem a paz liberal) e as inúmeras expressões de resistência local a essas reformas (MAC GINTY, 2010).

O debate sobre a paz híbrida constitui uma importante contribuição para a expansão da agenda da consolidação da paz. Primordialmente, esse debate sai da perspectiva mecanicista e de engenharia social que caracteriza as práticas políticas (e grande parte da literatura acadêmica sobre o tema). Ao fazer isso, traz à tona relações de poder antes "invisíveis", uma vez que os atores locais já não são mais vistos como passivos receptores de programas, mas agentes que podem acatar ou refutar a paz exportada (RICHMOND, 2011 e 2014; MAC GINTY; RICHMOND, 2013). Nessa agenda, abre-se espaço para a exploração de dinâmicas do cotidiano e para as inúmeras expressões de poder visto aqui circulando entre os diversos atores e não apenas sendo "imposto" de cima para baixo. Outro aspecto importante nesse debate é a dimensão da legitimidade associada às ações internacionais e como isso se reflete na sustentabilidade ou na crise da paz (ROBERTS, 2011; RICHMOND, 2014). Por fim, essa literatura abre espaço para que sejam discutidas questões de poder importantes no âmbito da relação entre os atores internacionais e os atores dos países onde as intervenções ocorrem. Nesse sentido, a "virada local" alterou de forma radical a perspectiva epistemológica subjacente ao debate sobre consolidação da paz.

Dito isso, há uma série de críticas e desafios analíticos ligados a essa literatura. Primeiramente, a ênfase na diferenciação entre o "internacional" e o "local" muitas vezes obscurece a porosidade entre esses níveis de análise. De um lado, existem atores "locais" (no sentido de serem nacionais que sempre viveram no país em questão) que são altamente internacionalizados - por exemplo, trabalham para ou receberam treinamento de agências internacionais (doadores, OIs e ONGs). Isso inclui boa parte da sociedade civil 
organizada, que é geralmente vista como importante representante dos interesses "locais". Ao mesmo tempo, e não obstante o esforço, na literatura, de diferenciar os atores locais que constituem a "elite" dos demais "locais" (RICHMOND, 2011), os "locais" são vistos predominantemente de forma homogênea e com grande potencial emancipador apesar de vários exemplos que contestam esse otimismo (HUGHES, 2015; MASCHIETTO, 2016) Ainda, essa visão otimista previne a própria crítica do hibridismo e de algumas estruturas criadas nesses contextos, que, em última instância, perpetuam formas de repressão não necessariamente associadas à dimensão norte-sul global (HUGHES et al., 2015; PAFFENHOLZ, 2015).

Outra crítica - que fundamenta o propósito deste artigo - é que, ainda que o objetivo da "virada local" seja mudar o foco da análise, no sentido de dar primazia à dimensão local e ao cotidiano, em última instância permanece um olhar fundamentalmente ocidental na medida em que o ponto de referência ainda é a paz liberal. As próprias manifestações de resistência, foco dessa literatura, apenas podem ser compreendidas em relação à paz liberal - o seu objeto de resistência. Assim, fica a seguinte pergunta: e as dinâmicas que não se relacionam diretamente com a paz liberal, nem em termos de cooperação nem de oposição? Como é possível capturá-las? Paffenholz (2015), por exemplo, nota a ausência de discussão sobre o engajamento dos Brics nesses cenários. Neste artigo, uma das perguntas que se colocam é: independentemente da paz liberal, quais são os valores norteadores da paz que caracterizam as sociedades em que tais intervenções ocorrem? O propósito desta reflexão é, portanto, ir além da ótica de choque e resistência e expandir a análise a fim de incorporar elementos que não necessariamente se apresentam de forma dicotômica no debate da paz liberal.

Tais críticas refletem a dimensão metodológica subjacente à virada local e capturada por Meera Sabaratnam (2013) quando fala em "avatares do Eurocentrismo". Em suas palavras, "não obstante o interesse crescente no 'cotidiano', atores 'locais' ou 'subalternos' nas sociedades pós-conflito e seus modos de 'resistência' ou 'hibridismo', as críticas têm falhado em discutir sistematicamente os problemas mais profundos de 'Eurocentrismo', em como pensamos e pesquisamos a política internacional" (SABARATNAM, 2013, p. 260, tradução nossa).

Ela identifica quatro problemas metodológicos ligados ao Eurocentrismo na literatura crítica sobre construção da paz. Em primeiro lugar, principalmente na primeira 
leva de literatura crítica, observa-se uma tendência em focar a problematização do Ocidente/dos interventores ao mesmo tempo em que se desvia a atenção dos atores que são o foco da intervenção. Ligado a isso, e em segundo lugar, observa-se a ênfase nas dinâmicas de governamentabilidade, que, uma vez mais, embora resulte na crítica ao “Ocidente/norte global”, tampouco auxilia a compreensão dos atores locais, em especial a exteriorização do poder dos agentes do "sul global", ou seja, em ambos os casos, passase por cima do sujeito local e se privilegia (mesmo que criticando) o interventor. Terceiro, ao se reproduzir a separação norte/sul em termos "moderno/tradicional", "local/internacional", dentre outras dicotomias, reproduz-se a ontologia do "outro", em que a diferença cultural aparece como o principal fator diferencial. Finalmente, e não obstante a crítica ao Ocidente, essa literatura reproduz um alto grau de "nostalgia pela política do contrato social, a democracia do bem-estar social e o sujeito político liberal", elementos ligados a uma perspectiva ainda ocidental (SABARATNAM, 2013, p. 268), o que é capturado essencialmente sobre o apelo emancipador dessa crítica.

Há que se notar que parte dessas críticas tem sido respondida pelos proponentes da "virada local". Em 2014, por exemplo, Richmond destacou a necessidade de se diferenciar entre formas positivas e negativas de paz híbrida. Em sua versão negativa, a paz híbrida traria a perpetuação de relações de poder e estruturas de dominação que levariam a exclusão e desigualdade. Em sua forma positiva, a paz híbrida seria oriunda do consenso mútuo entre os atores em torno de normas, valores, instituições, leis e direitos. O que contribuiria para o pêndulo positivo, nesse caso, seria o peso atribuído às dinâmicas de "formação da paz" (peace formation), onde residiria o potencial emancipatório da paz (RICHMOND, 2014).

Em 2015, Mac Ginty propôs uma revisão sobre a consideração do que seria o "local". Seu argumento propunha a reconsideração do "local" não como um sítio geográfico, mas como uma rede, um conjunto de atividade desterritorializado, ligado mais às pessoas que o constituem do que ao lugar em que as atividades acontecem. A partir dessa reconsideração conceitual seria possível pensar o "local" de forma mais complexa, crítica e refinada e evitar visões extremas (seja do local como "retrógrado", seja como a "salvação" para a efetividade da paz). Paralelamente, Kappler (2015) propôs a revisão da compreensão do local não como algo estático, mas como um processo constante de 
"localização e (des)(re)localização" em que os atores se reposicionam no âmbito social, político e econômico, navegando pelo espectro "local" e "global”.

Essas e outras respostas às críticas mostram o dinamismo da literatura da virada local, bem como os esforços dos autores para refinar esse debate. Nesse sentido, este artigo considera as críticas como um espaço profícuo para explorar elementos ainda incipientes na literatura. Conforme destacado por Richmond e Mac Ginty (2015) em artigo em que respondem de forma sistemática às críticas à "virada local”, a preocupação com o Eurocentrismo é uma constante na literatura e apresenta uma série de desafios metodológicos. Argumenta-se aqui que uma maior ênfase na dimensão subjetiva da paz é uma das formas de neutralizar esse viés eurocêntrico, pois se abre espaço para explorar elementos não necessariamente ligados à paz liberal.

Examinando a literatura existente sobre a "virada local", observa-se que, não obstante o potencial de alguns referenciais teóricos para examinar a dimensão subjetiva (e.g., o próprio framework de análise da paz híbrida proposta por Mac Ginty em 2010) e o próprio apelo cultural da virada local, ironicamente se nota a ausência de uma discussão mais aprofundada sobre certos aspectos culturais, em especial sobre as diferentes interpretações culturais a respeito da paz e das dinâmicas que escapam às ações mais manifestas de resistência à paz liberal. De fato, ao enfatizar as dinâmicas de resistência à paz liberal, a literatura crítica parece deixar implícito que os pilares da paz liberal são claros e visíveis como tal aos olhos dos atores locais. Mas em que medida as percepções locais de mudança a partir da paz se relacionam com esses elementos? Como os atores locais (para além da sociedade civil organizada) percebem e compreendem as mudanças oriundas desses processos? As próximas seções exploram essas questões apresentando alguns elementos para reflexão.

\section{INTERPRETAÇÕES SOBRE A PAZ: O PAPEL DA CULTURA E DA SUBJETIVIDADE NA ANÁLISE DA CONSOLIDAÇÃO DA PAZ}

A discussão acerca de segunda "virada local" advém da compreensão de que a paz liberal é uma construção cultural não necessariamente alinhada com outros contextos culturais (não ocidentais). Conforme sublinhado por Richmond (2011, p. 44, tradução nossa):

(...) os atores internacionais não consideram a consolidação da paz liberal como um produto específico da própria cultura. A conexão da consolidação da paz e da construção do Estado com as instituições liberais, o neoliberalismo e 
individualismo, em vez do contexto, da cultura ou das necessidades e do bemestar, ignora as experiências de reconstrução pós-guerra e o desenvolvimento do Estado liberal ocidental. 0 tipo de segurança que tende a ser produzido por essa abordagem inclina-se a ser de natureza internacional, regional e estatal, em vez de embasado na experiência e nas necessidades locais... Porém, mais significativa é a desconsideração da cultura como um local de agência de construção da paz.

Nesse sentido, essa perspectiva clama por uma virada pós-colonial no estudo da consolidação da paz que contextualiza conceitos previamente tidos como objetivos e neutros.

A ideia de cultura é fundamental nessa literatura. No entanto, aqui cultura está associada às diversas expressões de resistência em face da modernidade (RICHMOND, 2011). Parte-se, portanto, do pressuposto de que a modernidade - e as várias ações internacionais no sentido de exportar/impor modelos de governança e regulação social mundo afora - acaba por suprimir outras expressões culturais que, por sua vez, se ligam a outros modelos de gestão social. A ênfase, portanto, é na dinâmica de poder entre "dominadores" (os que pressionam pela perpetuação de um sistema de gestão "moderno") e "subalternos" (aqueles que rejeitam esse tipo de imposição e/ou que propagam modelos de controle social que fogem às dinâmicas da modernidade). Essa leitura baseia-se no pressuposto de que o conflito/choque de valores é fundamental para que possamos enxergar as visões dos "subalternos".

0 argumento apresentado neste artigo é que, não obstante essa leitura de fato permita observar fatores antes invisíveis na análise, em especial dinâmicas de conflito que passavam despercebidas na literatura mainstream sobre consolidação da paz, ela também dificulta a visualização de elementos que não necessariamente se alinham no espectro pró/antimodernidade, norte/sul, dominadores/subalternos e outras dicotomias associadas a este debate. Assim, sugere-se aqui sair um pouco da ênfase no conflito de perspectivas e simplesmente tentar observar os elementos culturais e normativos que sustentam a vasta miríade de interpretações sobre a paz nos respectivos âmbitos locais.

A discussão acerca da paz liberal é em grande medida baseada na concepção de paz como "ausência de guerra". O propósito primordial é eliminar a eclosão de violência direta organizada. As medidas propostas - ligadas a reforma do Estado, democracia, liberalização econômica, etc. - são justificadas por sua suposta contribuição na prevenção da recorrência de violência direta a longo prazo, ou seja, mesmo a proposição de que, em sua vertente emancipadora, a paz liberal almeje alguma forma de justiça social (paz 
positiva), ainda o ímpeto que guia essas ações é a crença de que, atingidas certas condições estruturais (bem-estar social, direitos humanos, justiça, etc.), isso, por sua vez, vai prevenir a recorrência de violência direta. Em suma, parte-se do pressuposto de que a violência estrutural contribua para a violência direta, daí a necessidade de superar ambas a fim de se atingir uma paz duradoura.

No fundo, ainda que a noção de paz positiva represente um conceito mais amplo e normativamente mais complexo do que paz como "ausência de guerra/violência direta", ainda assim esse conceito carrega traços eminentemente ocidentais. De fato, e ironicamente, embora a "virada local" se baseie na crítica ao caráter universalista da paz liberal, os próprios valores subjacentes à ideia de emancipação também apresentam um contorno cultural influenciado pelo viés ocidental de liberdade individual. Ao expandirmos o debate para uma concepção cultural mais abrangente de paz, no entanto, percebemos que existem diversas cosmologias subjacentes a esse conceito que são fundamentalmente diferentes daqueles que dão sustentação ao debate sobre consolidação da paz.

Já em 1981, por exemplo, Galtung discutiu o contraste entre as cosmologias sociais de paz dominantes no Ocidente e aquelas dominantes no Oriente. Ele notou, por exemplo, que, nas tradições ocidentais, o conceito de paz é percebido compondo o caráter de um sistema (intra/interpessoal, intra/intersocietal e intraglobal). Isso leva a duas implicações importantes. Primeiramente, a definição de paz no Ocidente ficou diretamente associada à distinção entre "in-group" e "out-group", ou seja, à divisão entre aqueles que pertencem ao sistema e aqueles que estão fora dele. Segundo, e como consequência disso, houve uma tendência a se universalizar a paz (tornar todos parte do mesmo sistema) (GALTUNG, 1981).

Galtung ainda observou como essa visão contrasta com as visões mais orientais da paz. No Oriente, há bem menos preocupação com a arquitetura da paz em geral; pelo contrário, a preocupação central é o ser humano enfrentar a si próprio, uma vez que o objetivo final tem não apenas dimensões extrovertidas (paz para o universo), mas também uma importante dimensão introvertida, qual “a paz na própria alma, paz intrapessoal, harmonia da mente" (GALTUNG, 1981, p. 191, tradução nossa), ou seja, o fundamento normativo e ontológico da paz é diferente. Por uma perspectiva cultural oriental, portanto, toda a racionalidade subjacente à ideia de "peacebuilding" não faria o 
menor sentido, pois o objetivo final da paz teria outra natureza, uma de caráter muito mais subjetivo e intangível.

Mais recentemente, Dietrich (2014) propôs uma tipologia de interpretações da paz a partir dos valores norteadores centrais a cada grupo conceitual, considerando as diversas culturas no mundo. A tipologia consiste nas seguintes categorias: (1) interpretações energéticas da paz, que enfatizam a ideia de harmonia (inclusive com a natureza e o cosmo); (2) interpretações morais da paz, que enfatizam a justiça; (3) interpretações modernas da paz, que enfocam questões de segurança; e (4) interpretações pós-modernas que lidam com questões ligadas à "verdade". Tal como Galtung, Dietrich nota que algumas dessas interpretações (as morais e as modernas) possuem um apelo universalista, enquanto as demais enfatizam o papel da diferença. Mais importante, no entanto, é que essa tipologia ressalta a diferente finalidade de cada abordagem e traz questionamentos importantes no debate sobre a consolidação da paz. Por exemplo, no continente africano predominam interpretações energéticas sobre a paz; contudo, as operações de paz estão fundamentalmente baseadas nas abordagens modernas e morais. Nesse caso, parece pertinente perguntar: “Em que medida a 'paz' promovida é percebida como 'paz' pelos atores 'locais'? Ao mesmo tempo, se a visão de paz que prevalece localmente é energética, como as reformas institucionais afetam essa visão ou, contrariamente, como a visão local influencia as reações locais perante essas reformas? Há, ao final, uma 'fusão' dessas visões de paz?" Tais questões são pertinentes no que concerne à compreensão dos efeitos das ações internacionais para a paz e para sua própria sustentabilidade e qualidade.

É importante notar que, além da dimensão cultural, o histórico de violência e paz de cada povo/país/grupo social também influencia as percepções e definições acerca desses conceitos. Aliás, sendo a cultura algo em constante movimento, cabe considerar que ela mesma pode mudar e ser diretamente influenciada por determinados eventos, em especial os traumáticos, como guerras e outras formas de violência prolongada. Ao mesmo tempo, num contexto global em que as fronteiras são cada vez mais porosas, nenhuma cultura está isolada; ao contrário, é plausível considerar que o grau de penetrabilidade de influências culturais exógenas (inclusive por meio de doadores, ONGs, projetos de cooperação) seja cada vez maior, afetando o desenvolvimento de culturas previamente mais fechadas ou isoladas. 
No que concerne à paz, é interessante notar ainda que, apesar das diferenças culturais e diferentes visões cosmológicas, existem certos valores que são encontrados universalmente quando se fala sobre paz. Em 2013, foi publicado um amplo estudo comparativo, de escala global, baseado em grounded theory, sobre definições de "paz" e "reconciliação" (MALLEY-MORRISON et al., 2013). ${ }^{3}$ Os resultados foram agrupados em oito grupos regionais e codificados de acordo com as respostas recebidas. No caso das definições de paz, três grandes categorias destacaram-se: definições que privilegiavam o aspecto negativo da paz (o que ela não é), definições que privilegiavam o que ela é/deveria ser (aspectos positivos, incluindo elementos intangíveis, como tranquilidade e harmonia) e definições voltadas para a possibilidade de concretização ou não da paz ("attainability"). É notável que em todas as regiões tenha havido respostas que exibiam aspectos ligados a cada uma dessas categorias. Ao mesmo tempo, a proporção da ênfase em uma ou outra e suas respectivas subcategorias apresentaram variações significativas entre regiões, refletindo a história de cada região, bem como fatores culturais. Por exemplo, enquanto, na Europa Ocidental, 40\% das respostas se encaixaram na categoria "paz negativa", no caso dos países anglo-saxões (inclusos Reino Unidos, Estados Unidos e Austrália) esse percentual foi de 49\%, e, na África, de apenas 32\% (não obstante esse seja hoje um dos continentes com mais conflitos armados, o que poderia levar a crer que a referência à violência direta fosse predominante). Em contrapartida, as referências a elementos que refletiam aspectos positivos da paz apareceram em $45 \%$ das respostas na Europa Ocidental, em comparação com 40\% nos países anglo-saxões, 47\% na África e 51\% no Sudeste Asiático. No que concerne aos requisitos identificados para a paz positiva, na África houve significativa referência a "acesso a recursos", um elemento que não apareceu de forma significativa nas duas outras regiões e que remonta a elementos de discussão da “paz positiva' enquanto condição estrutural. Ao mesmo tempo, nesse continente e no Sudeste Asiático, por exemplo, também houve maior referência a "harmonia”, "emoções positivas" e "calma e tranquilidade'” em comparação à Europa Ocidental, mas não muito mais do que no caso dos países anglo-saxões.

Essa breve consideração sobre a dimensão cultural da paz reforça a ideia de que uma visão demasiado binária na análise da cultura, como tem sido predominante na

\footnotetext{
3 Neste parágrafo, os dados referentes à África referem-se ao capítulo de Dalley et el. (2013); os referentes à Europa Ocidental, Salmberg et al. (2013); os referentes aos países anglófonos, Page et al. (2013); e os referentes ao Sudeste Asiático, Jones et al. (2013).
} 
"virada local", não abrange a complexidade do debate sobre cultura e sua relação com a consolidação da paz. Primeiramente, da mesma forma que existem disputas por discurso sobre o próprio conteúdo da "paz liberal”, existem inúmeros elementos de aproximação entre as diversas formas como pessoas em variadas regiões do mundo entendem o conceito de paz. Em segundo lugar, as variações de interpretações sobre paz dentro de cada região, conforme o estudo de Malley-Morrison et al. (2013), levam ao questionamento se acaso não há outras dicotomias que poderiam explicar as diferentes visões de paz, como, por exemplo, a fronteira rural/urbana, as questões de gênero e escolaridade, dentre outras. Nesse sentido, reforça-se a ideia de que a dimensão cultural da paz deve ser considerada na análise de sua consolidação para além das dinâmicas de resistência à paz liberal, bem como de forma associada ao contexto histórico. Ao mesmo tempo, se faz necessário diferenciar o que seria o discurso utilizado para justificar as atividades de consolidação da paz (assim como seu contesto político) da expressão cultural social mais ampla de cada localidade acerca da paz.

A próxima seção discute como essas variações/semelhanças culturais sobre a paz interagem com ou se distanciam da lógica da paz liberal subjacente às ações de consolidação da paz.

\section{CONSOLIDAÇÃO DA PAZ E PERCEPÇÕES LOCAIS: ENCONTROS E DESENCONTROS}

A partir do alinhamento ou gap que existe entre a dimensão cultural que sustenta a paz liberal e as visões de paz dos atores locais de onde ocorrem as intervenções, podemos identificar quatro dinâmicas distintas.

(1) Primeiramente, há pontos de convergência em relação às expectativas ligadas à consolidação da paz liberal e às expectativas locais.

(2) Segundo, há expressões de rejeição e resistência a certos traços das políticas associadas à paz liberal, conforme discutido na literatura sobre paz híbrida.

(3) Terceiro, é possível identificar expectativas locais sobre a paz que não são priorizadas ou sequer incorporadas na agenda da paz liberal.

(4) Por fim, há elementos que constituem parte central da paz liberal e que parecem não ter qualquer ressonância (nem de alinhamento nem de oposição) com a noção de paz pela ótica local. 
Nesta seção será utilizado o caso de Moçambique como plataforma para observar algumas dessas dinâmicas.

Moçambique obteve sua independência de Portugal em 1975, sob a liderança da Frente de Libertação de Moçambique (Frelimo). Em 1977, ano em que a Frelimo assumiu declaradamente um governo de orientação marxista-leninista, o país passou a sofrer ataques de grupos sediados no vizinho Zimbábue (então Rodésia do Sul), ainda governado por uma minoria branca. A partir de 1980, após a independência do Zimbábue, esses grupos, agora coadunados sob o nome de Resistência Nacional Moçambicana (Renamo), passaram a ter o apoio massivo do governo do apartheid da África do Sul.

Em tempo, o que começou como uma guerra de desestabilização assumiu contornos cada vez mais internos. 0 fracasso da Frelimo em reestruturar a economia do país após a independência, aliado às calamidades naturais que marcaram a década de 1980 e aos contornos cada vez mais cruéis da guerra, afetou a legitimidade do governo. 0 acordo de paz de 1992 refletiu, dentre outros fatores, uma situação de impasse entre o governo da Frelimo e a Renamo (SYNGE, 1997).

0 processo de mediação coletiva que levou à assinatura dos acordos de paz e o período imediato após os acordos foram considerados um enorme sucesso. Apesar de algumas críticas, a ONUMOZ, operação das Nações Unidas para monitorar as primeiras eleições, foi considerada eficaz ao prevenir a retomada da violência, mesmo diante das tensões que surgiram no meio do processo (CABAÇO, 1995; SYNGE, 1997). Em pouco tempo, Moçambique tornou-se um caso de sucesso no âmbito da ONU e das operações de paz: apesar de alguns incidentes, as eleições foram consideradas justas e a oposição aceitou o resultado, transformando-se de grupo rebelde a partido político atuante no novo governo; ao mesmo tempo, o processo de liberalização econômica, que vinha sendo imposto pelas instituições financeiras internacionais desde a segunda metade da década de 1980, acelerou-se radicalmente. À primeira vista, a paz (neo)liberal parecia efetiva e funcional (MASCHIETTO, 2016).

Há que se destacar, no entanto, que, em grande medida, embora bem menos publicizado, o sucesso imediato (e a longo prazo) da paz em Moçambique se deu em razão da própria vontade dos moçambicanos. De fato, enquanto as negociações de paz aconteciam entre a Renamo e a Frelimo, inúmeras iniciativas já vinham ocorrendo em nível local, onde as comunidades se organizaram a fim de construir a paz no seu dia a dia. 
Aqui, a preocupação central não era com o novo formato institucional do Estado, mas com a reintegração social dos ex-soldados, inclusive crianças soldados, por meio de rituais de limpeza espiritual e reconciliação (HONWANA, 1996; VAN DEN BERGH, 2009).

Não que as mudanças formais não fossem importantes; pelo contrário, naquele momento, ambas se complementaram. No entanto, após mais de 20 anos, enquanto as comunidades mostram extrema resiliência e comprometimento com a paz, as reformas institucionais implementadas a partir de 1992 estão sendo fruto de mais uma contestação armada. ${ }^{4}$ Enquanto os fatores que levaram à retomada do conflito têm sido amplamente discutidos pela ótica das elites políticas envolvidas, o objetivo desta seção é questionar como as reformas implementadas desde 1992 têm sido percebidas pela população em geral, especialmente pela maioria que reside ainda na zona rural e é dependente de agricultura de subsistência.

Os parágrafos a seguir são baseados em pesquisa realizada em 2012 e tiveram como questão central: "Qual é a percepção de mudança das comunidades desde o fim da guerra?" (MASCHIETTO, 2015). Embora ligadas a uma pesquisa anterior, centrada na compreensão das dinâmicas de empoderamento local, algumas questões identificadas dialogam diretamente com a pesquisa em andamento e exemplificam os quatro cenários identificados acima.

Primeiramente, as atividades realizadas com os atores locais mostraram que existe uma diferença central no que concerne às expectativas ligadas à paz liberal e às expectativas das pessoas no cotidiano. Enquanto a agenda da paz liberal enfoca planos de grande porte ligados à reforma do Estado, em nível local a ideia de "mudanças oriundas da paz" remete a fatores concretos do dia a dia, muito menos ambiciosos, como acesso a serviços de infraestrutura (escolas, hospitais/postos de saúde, estradas funcionais, acesso a eletricidade e água potável, dentre outros). Uma vez que o cerne da agenda da paz liberal reside em (re)constituir e fortalecer macroestruturas (democracia, economia de mercado e instituições do Estado) que eventualmente (ou assim se sugere) levarão a outras melhorias a longo prazo, esses outros elementos não são priorizados. Assim, no caso de

\footnotetext{
${ }^{4}$ Em 2013, o líder da Renamo Afonso Dhlakama colocou fim aos acordos de paz de 1992 e retomou as armas como forma de exercer pressão para que o governo conduzisse uma série de reformas políticas e no âmbito das Forças Armadas. Embora um novo acordo de paz tenha sido assinado em setembro do mesmo ano, até o momento da submissão deste artigo, o conflito continua, paralelamente às negociações.
} 
Moçambique, depois de 20 anos da assinatura dos acordos de paz e da instalação de uma democracia formal, e ainda mais tempo após a abertura comercial, a falta de acesso a postos de saúde, água potável e escolas é um problema ainda extremamente comum na zona rural, não obstante algumas melhorias.

Dito isso, há um elemento básico que é central na agenda da paz liberal e que teve enorme ressonância nas respostas locais: a paz entendida como fim da violência direta expressa como o fim da constante pressão de fugir de mato em mato e, finalmente, poder constituir família, residir no mesmo lugar e não temer pela própria vida. Obviamente, esse é um objetivo crucial na agenda internacional da paz, embora, no caso da paz liberal, o objetivo também inclua a prevenção da recorrência dessa violência a longo prazo - daí as reformas políticas e econômicas. Mas é justamente aqui que é possível observar, no caso de Moçambique, elementos de resistência e falta de ressonância.

Em locais recônditos, onde o meio de sobrevivência da família é dependente da venda de produtos agrícolas (de produção familiar em pequena escala), a liberalização econômica não é necessariamente vista com bons olhos. Como notaram alguns agricultores, a ausência de regulação dos preços das mercadorias pelo Estado, junto com as péssimas condições de transporte e falta de recursos - que leva à inabilidade de o produtor poder escoar seus produtos na cidade -, faz com que eles sejam forçados a vender sua produção a quem quer que apareça no interior, diminuindo seu poder de barganha e muitas vezes levando a um lucro extremamente baixo, que acaba sendo utilizado para necessidades familiares básicas e não para novo investimento (MASCHIETTO, 2015).

Ao mesmo tempo, a ênfase nas reformas democráticas - centrais na agenda da paz liberal - não necessariamente encontra ressonância na ótica dos cidadãos da zona rural. Ao serem questionados sobre "o que mudou com a paz", nunca fizeram alusão a eleições ou democracia. Não que o tema não seja reconhecido como importante, em especial por participantes diretamente engajados em organizações da sociedade civil, ou das camadas mais urbanas, em que o tema democracia (em especial como liberdade de expressão e representação) é prioritário. No entanto, o fato de esse elemento, tão crucial na agenda da consolidação da paz, não ser mencionado de forma direta no meio rural traz um questionamento importante sobre como os habitantes locais entendem a relação da 
democracia (ocidental) com a paz e como as reformas democráticas implementadas afetaram questões de cidadania, participação e representatividade no âmbito local.

Pesquisas de opinião feitas pelo Afrobarometer (2002 e 2012) em Moçambique ilustram a complexidade da implementação da democracia nesse país e chamam a atenção para dois elementos importantes. Primeiramente, a democracia é compreendida não apenas como um exercício político, mas como algo que se relaciona com direitos econômicos. Segundo, é impossível entender a paz e a democracia em Moçambique sem fazer referência ao medo (de se expressar, de contestar, de gerar conflito social), um tema ausente na agenda da paz liberal e que perpassa não apenas a relação cidadão-Estado, mas também a relação cidadão-comunidade (MASCHIETTO, 2016).

Cabe ressaltar que a heterogeneidade do local também afeta a forma como os cenários delineados acima serão interpretados. Além da diferença entre populações urbanas/sociedade civil e rural, existem diferenças importantes no âmbito micro que influenciam como cada ator é afetado pelas ações que perpassam a consolidação da paz. Isso leva a uma discussão mais profunda, que também merece mais discussão na análise crítica da consolidação da paz e que demanda a problematização sobre poder e percepções de poder (MASCHIETTO, 2016).

\section{CONCLUSÃO}

O presente artigo teve por objetivo problematizar a discussão acerca da "virada local" na análise da consolidação da paz, chamando a atenção para a dimensão cultural e subjetiva que não necessariamente se alinha ou se opõe à agenda da paz liberal, ponto de partida da virada local. Conforme discutido, a ênfase nas dinâmicas de resistência no debate sobre a paz híbrida - conceito-chave nesse debate - advém dos próprios contornos do debate sobre cultura que sustenta essa crítica e que põe ênfase nas expressões de resistência como manifestação primordial da cultura local.

Não há dúvidas de que expressões de resistência sejam importantes para a compreensão das limitações das ações de consolidação da paz. Há que se considerar, no entanto, que a ênfase na resistência pode igualmente esconder outros aspectos ligados à cultura que não sejam diretamente compreendidos a partir de relações de oposição ou alinhamento. De fato, ao se enfocar resistência/alinhamento, a consequência é que a análise da consolidação da paz fica presa na própria discussão (aceitação ou rechaça) da 
paz liberal, perdendo-se a perspectiva mais ampla, que pode, em última instância, englobar outros elementos que não necessariamente se alinhem nesse binômio.

0 argumento do artigo enfoca, portanto, a necessidade de equilibrar a perspectiva cultural que pauta o debate sobre consolidação da paz, de forma a não se fixar na perspectiva da resistência, mas, sim, englobar dinâmicas subjetivas mais genéricas que incluam a própria discussão sobre a ontologia da paz segundo as diferentes visões cosmológicas das sociedades nas quais as ações internacionais acontecem. A partir disso, é possível não apenas observar padrões de resistência, alinhamento ou cooptação, mas também elementos que perpassam esse tipo de classificação e que, no entanto, afetam a forma como os atores locais respondem às reformas desenhadas na agenda da consolidação da paz.

\section{Referências bibliográficas}

BOEGE, V.; BROWN, A.; CLEMENTS, K.; NOLAN, A. On hybrid political orders and emerging states: what is failing - States in the global South or research politics in the West? Berghof Handbook for Conflict Transformation. Berghof Research Center, 2009.

BORGES, Marisa; MASCHIETTO, Roberta H. Cidadania e empoderamento local em contextos de construção da paz. Revista Crítica de Ciências Sociais, 105, 65-84, 2014. Disponível em: http://rccs.revues.org/5800

BORGES, Marisa; MASCHIETTO, Roberta H. Peacebuilding, citizenship and empowerment. Trabalho apresentado na 57a Convenção Anual da International Studies Association (ISA), "Exploring Peace”, Atlanta, 16-19 de Março, 2016.

CABAÇO, José Luis. A Longa Estrada da Democracia Moçambicana. In: Mazula, B. (ed.) Moçambique. Eleições, Democracia e Desenvolvimento. Maputo, 79-114, 1995.

CHANDLER, David. Empire in Denial. The Politics of State-building. London: Pluto Press, 2006.

DALLEY, Mahlon; HEINECKE, Jennifer, AKHURST, Jacqueline; ABDELALI, Abdelkader; SCRUGGS, Natoschia; DEBARTOLO, Raquel; FAMOSE, Adeniyi; CASTANHEIRA, Helena; CORREIA, Eduardo, TASTLE, William. Definitions of peace and reconciliation in Africa. MALLEY-MORRISON, K.; MERCURIO, A.; TWOSE, G. (eds.) International Handbook of Peace and Reconciliation. New York: Springer, 2013, 81-97.

DIETRICH, Wofgang. A Brief Introduction to Transrational Peace Research and Elicitive Conflict Transformation, Journal of Conflictology, 5, 2, 48-57, 2014.

DONAIS, Timothy. Peacebuilding and Local Ownership. Post-Conflict Consensus-Building. Series: Conflict, Development and Peacebuilding. London: Routledge, 2012.

FETHERSTON, A. Betts. Peacekeeping, conflict resolution and peacebuilding: A reconsideration of theoretical frameworks. International Peacekeeping, 7, 1, 190-218, 2000. 
GALTUNG, Johan. Social Cosmology and the Concept of Peace. Journal of Peace Research, 2(XVIII), 183-199, 1981.

HEATHERSHAW, John. Unpacking the Liberal Peace: The Dividing and Merging of Peacebuilding Discourses. Millennium - Journal of International Studies, 36; 597, 2008.

HONWANA, Alcinda M.R. M. Spiritual Agency and Self-Renewal in Southern Mozambique. Thesis Submitted for the Dregree of Doctor of Philosophy in Social Anthropology, School of Oriental and African Studies, University of London, London, 1996.

HUGHES, C.; ÖJENDAL, J.; SCHIERENBECK, I. The struggle versus the song - the local turn in peacebuilding: an introduction. Third World Quarterly, 36, 5, 817-824, 2015.

HUGHES, Caroline. Poor people's politics in East Timor Caroline. Third World Quarterly, 36, 5, 908-928, 2015.

JONES, Janice; DIEHNELT, E.E.; SHAHANE, Anoushka; PURI, Ellora; SHAH, Darshini; ESTUAR, Ma. Regina E.; MCCARTHY, Sherri; REIF, Megan; MUHAMMAD, Haslina; RAJ, Nisha; JAFFAR, Jas. Definitions of Peace and reconciliation in South and Southeast Asia. MALLEY-MORRISON, K.; MERCURIO, A.; TWOSE, G. (eds.) International Handbook of Peace and Reconciliation. New York: Springer, 2013, 107116.

KAPPLER, Stefanie. The dynamic local: delocalisation and (re-)localisation in the search for peacebuilding identity. Third World Quarterly, 36:5, 875-889, 2015.

LEDERACH, John Paul. Building peace. Sustainable reconciliation in divided societies. Washington, DC: United States Institute of Peace Press, 1997.

MAC GINTY, Roger; RICHMOND, Oliver P. The Local Turn in Peace Building: a Critical Agenda for Peace. Third World Quarterly, 34 (5), 763-783, 2013.

MAC GINTY, Roger. Hybrid Peace: the Interaction between Top-Down and Bottom-Up Peace. Security Dialogue, 41, 4, 391-412, 2010.

MAC GINTY, Roger. No War, No Peace. The Rejuvenation of Stalled Peace Processes and Peace Accords. Basingstoke, New York: Palgrave Macmillan, 2006.

MAC GINTY, Roger. Where is the local? Critical localism and peacebuilding, Third World Quarterly, 36:5, 840-856, 2015.

MALLEY-MORRISON, K.; MERCURIO, A.; TWOSE, G. (eds.) International Handbook of Peace and Reconciliation. New York: Springer, 2013.

MANNING, Carrie. The Politics of Peace in Mozambique. Post-Conflict Democratization, 1992-2000. Westport, London, Connecticut: Praeger, 2002.

MASCHIETTO, Roberta H. Beyond Peacebuilding. The Challenges of Empowerment Promotion in Mozambique. Series: Rethinking Peace and Conflict Studies, London: Palgrave Macmillan, 2016.

MASCHIETT0, Roberta H. What Has Changed with Peace? Local Perceptions of Empowerment in Mozambique. Journal of Peacebuilding and Development, 10, 2, 2035, 2015.

PAFFENHOLZ, Thania. Unpacking the Local Turn in Peacebuilding: a Critical Assessment Towards an Agenda for Future Research. Third World Quarterly, 36, 5, 857-874, 2015. 
PAGE, James; AN, Sarah; WHITELY, Michael; WEST, Doe; DAVIS, John; DAVIS, Carol. Definitions of Peace and reconciliation in Great Britain, Northern Ireland, Canada, the United States, and Australia. MALLEY-MORRISON, K.; MERCURIO, A.; TWOSE, G. (eds.) International Handbook of Peace and Reconciliation. New York: Springer, 2013, 35-49.

PARIS, Roland. At War's End. Building Peace After Civil Conflict. Cambridge: Cambridge University Press, 2004.

PUGH, M.; COOPER, N; TURNER, M. (eds.) Whose Peace? Critical Perspectives on the Political Economy of Peacebuilding, Second Edition, New Security Challenges Series (Ed. by CROFT, Stuart), Houndmills, Basingstoke, Hampshire: Palgrave Macmillan, 2011.

PUGH, Michael. Welfare in War-Torn Societies: Nemesis of the Liberal Peace? In: RICHMOND, Oliver P. (ed.) Palgrave Advances in Peacebuilding. Critical Developments and Approaches. Houndmils, Basingstoke: Palgrave Macmillan, 2010, 262-278.

RAMSBOTHAM, O.; WOODHOUSE, T.; MIALL, H. Contemporary Conflict Resolution. 2nd edn. Cambridge, Malde: Polity, 2005.

RICHMOND, Oliver P. A Post-Liberal Peace. London, New York: Routledge, 2011.

RICHMOND, Oliver P. Failed Statebuilding. Intervention, the State, and the Dynamics of Peace Formation. New Haven and London, Yale University Press, 2014.

RICHMOND, Oliver P. The problem of peace: understanding the 'liberal peace'. Conflict, Security and Development, 6, 3, 291-314, 2006.

RICHMOND, Oliver P. The Transformation of Peace. Houndmills, Basingstoke, Hampshire: Palgrave Macmillan, 2005.

RICHMOND, Oliver P.; MAC GINTY, Roger. Where now for the critique of the liberal peace? Cooperation and Conflict, 50, 2, 171-189, 2015.

ROBERTS, David. Post-Conflict Peacebuilding, Liberal Irrelevance and the Locus of Legitimacy. International Peacekeeping, 18, 4, 410-42, 2011.

SABARATNAM, Meera. Avatars of Eurocentrism in the critique of the liberal peace. Security Dialogue, 44(3), 259-278.

SABARATNAM, Meera. The Liberal Peace? An Intellectual History of International Conflict Management, 1990-2010. In: CAMPBELL, S.; CHANDLER, D.; SARABATNAM, M. (eds.) A Liberal Peace? The Problems and Practices of Peacebuilding. London, New York: Zed Books, 2011.

SALMBERG, Mathilde; O'KEEFE, Kathryn; AN Sarah; MACHADO, Carla; OMARSDOTTIR, Silja B.; CORGAN, Michael; BARBOSA, Mariana; KÖNIG, Julia; LEEMBRUGGENKALLBERG, Elizabeth; ROLAND-LEVY, Christine. Definitions of Peace and reconciliation in Western Europe. MALLEY-MORRISON, K.; MERCURIO, A.; TWOSE, G. (eds.) International Handbook of Peace and Reconciliation. New York: Springer, 2013, 23-32.

SELBY, Jan. The myth of liberal peace-building. Conflict, Security \& Development, 13, 1, 57-86, 2013.

SYNGE, Richard. Mozambique. UN Peacekeeping in Action, 1992-94. Washington DC:

United States Institute of Peace Press, 1997. 
VAN DEN BERGH, Lucia. Why Peace Worked. Mozambicans Look Back. AWEPA, Association of European Parliamentarians with Africa, 2009.

WILLETT, Susan. Trading with Security: Trade Liberalisation and Conflict. In: PUGH, M.; COOPER, N; TURner, M. (eds.) Whose Peace? Critical Perspectives on the Political Economy of Peacebuilding, Second Edition, New Security Challenges Series (Ed. by CROFT, Stuart), Houndmills, Basingstoke, Hampshire: Palgrave Macmillan, 67-84, 2011.

ZÜRCHER, Christoph. The Liberal Peace: a Tough Sell? In: Campbell, S.; Chandler, D.; Sabaratnam, M. (eds.) A Liberal Peace? The Problems and Practices of Peacebuilding. London, New York: Zed Books, 69-88, 2011. 